\title{
P-type properties of micro and nano-structured carbon films from hydrocarbon palm oil in photovoltaic heterojunction solar cell applications
}

\author{
A. Ishak ${ }^{1,3}$, M. Rusop ${ }^{1,2}$ \\ ${ }^{I}$ NANO-Electronic Centre, Faculty of Electrical Engineering, Universiti Teknologi MARA, 40450 Shah Alam \\ Selangor, Malaysia \\ ${ }^{2}$ NANO-SciTech Centre, Institute of Science, Universiti Teknologi MARA, 40450 Shah Alam, Selangor, \\ Malaysia \\ ${ }^{3}$ Faculty of Electrical Engineering UiTM Kampus Kota Samarahan, Jalan Meranek, Sarawak
}

\begin{abstract}
The micro and nano-structured amorphous carbon as p-type films prepared from natural palm oil precursor for heterojunction solar cell were presented. Field-emission scanning electron microscopy (FESEM) revealed the micro and nano structured films had particle size in the range of $382 \mathrm{~nm}$ to $689 \mathrm{~nm}$ and 28 to 34 $n m$, respectively. The energy-dispersive spectroscopy $(E D S)$ showed the existing of carbon in micro-structured amorphous carbon film and carbon together with boron in nano-structured amorphous carbon film. Solar simulator analysis results showed an open circuit voltage (VOC), current density (JSC), fill-factor(FF) and conversion efficiency ( $\eta$ ) of Au/a-C/n-Si/Au were $264.62 \mathrm{mV}, 1.50434 \mathrm{~mA} / \mathrm{cm} 2,0.32632$, and $0.130154 \%$, respectively. Meanwhile, the VOC, JSC, FF and $\eta$ of Au/a-C:B/n-Si/Au solar cell were $271.25 \mathrm{mV}, 14.91723$ $\mathrm{mA} / \mathrm{cm} 2,0.33582$, and $1.542622 \%$, respectively. The conversion efficiency was increased as the p-type film was in nanostructure form.

Keywords :Amorphous carbon, Palm-oil, Negative bias, Boron doping, Carbon film, Carbon solar cell
\end{abstract}

\section{INTRODUCTION}

Various types of carbon precursors have been discovered from renewable precursors; camphor powder, turpentine oil, coconut oil, etc [1,2] and non-renewable sources; methane, acetylene, ethanol and eylene for producing allotrope carbon such as carbon nano tubes (CNT), graphene, amorphous carbon, etc. using various method of depositions [1,2]. Beside of those precursors, palm oil the other abundantly promising 'green' source was successfully synthesized the vertically aligned carbon nanotubes (VACNTs). Palm oil is scientifically known as hexaeconoic acid which was derived from fibrous exocorp and mesacarp of the fruits of palm tree. The palm oil is contained carbon (67), hydrogen (127) and oxygen (8) to form the chemical binding of $\mathrm{C}_{67} \mathrm{H}_{127} \mathrm{O}_{8}$ (3). This compound has the highest carbon content among the known precursors. The synthesizing of $\mathrm{a}-\mathrm{C}$ on the other hand, required less energy compared with other allotropes carbon for instant, the VACNTs need deposition temperature above $700^{\circ} \mathrm{C}$ [1]. Nevertheless, the a-C films are weak $p$-type in nature and they possess complex structure and high density of defects, thereby restricting their doping capacity; this low doping efficiency is the main obstacle for their application in various electronic devices. Amorphous carbon (a-C) films have gained considerable attention because of their controllable optical gap, which allows for its wide application in the manufacture of semiconductors. In order to solve that problem, it was suggested; the control of doping could reduce the existing of defect and at the same time modified the electronic properties [3-5].

Among deposition parameters, negative bias voltage applied to the substrates could significantly change film properties due to enhancement of adatom mobility and the effects of ion bombardment. The ion bombardment during coating deposition would play an important role in affecting the morphology, structure, composition and mechanical properties of coatings [6,7]. Many attempts were studied by others on the effect of negative bias for instant through the use of pure lubricant coatings $\left(\mathrm{MoS}_{2}\right)$ composite film. It was reported that, the increase of bias caused preferential re-sputtering of $\mathrm{S}$ resulting in a reduced S/Mo ratio, which can affect different properties of the film. A reported study on pure $\mathrm{MoS}_{\mathrm{x}}$ films deposited by bipolar pulsed DC showed that even an S/Mo ratio of 0.8 was able to provide good lubricious property due to the strong basal plane orientation and application of a bias voltage was found to reduce the coefficient of friction [8-10]. Therefore, an understanding of substrate bias effects is necessary to improve the physical and mechanical properties of $\mathrm{MoS}_{2^{-}}$ based coatings but also important for structural, electrical as well as electronic properties of any semiconductor film.

In this paper, we report the micro-structured of as-deposited and nano-structured of boron doped amorphous carbon films deposited by using deposition temperature without bias $(0 \mathrm{~V})$ and deposition temperature with the help of a constant negative bias $(-20 \mathrm{~V})$. To the best of our knowledge, there is less report 
on natural bio-hydrocarbon of palm oil as a p-type of a-C film for heterojunction solar cell using negative bias technique.

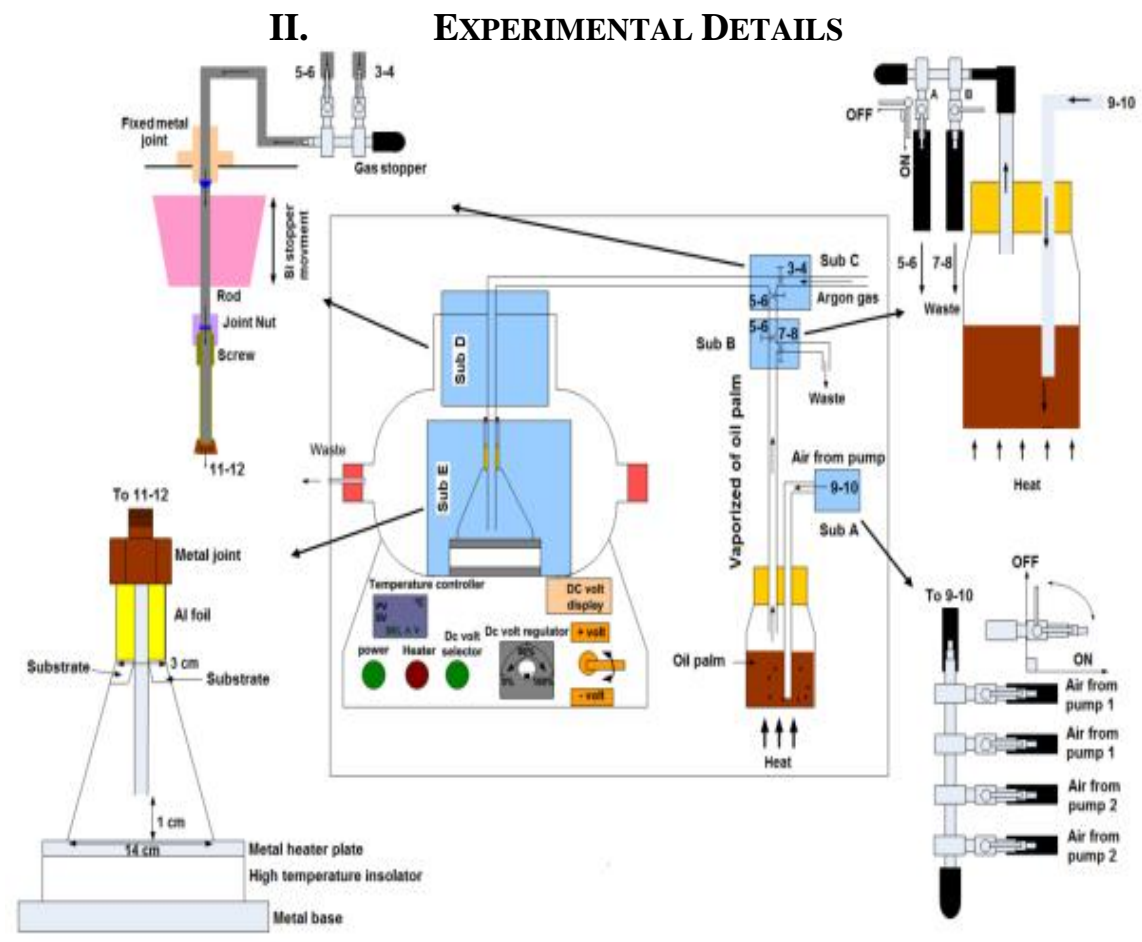

Figure 1. A schematic diagram of bias assisted pyrolysis-CVD

The micro-structured a-C and nano-structured a-C:B films were deposited by using bias-assisted pyrolysisCVD onto n-silicon (thickness $325 \pm 25 \mu \mathrm{m}$, resistivity 1-10 $\Omega \mathrm{cm}$ ) and glass substrate $(1 \mathrm{~mm})$. Substrate was cleaned with acetone followed by methanol for $15 \mathrm{~min}$ in Ultrasonic Cleaner (power Sonic 405), respectively. Excess oxide layers were etched using diluted hydrofluoric acid and DI water with a ratio of 10:1 for about 2 min before rinsing in DI water. The substrates were dried with nitrogen gas and placed inside the chamber.

The deposition substrate temperature was set at $350^{\circ} \mathrm{C}$ for $1 \mathrm{~h}$ deposition with a constant of negative bias voltage $-20 \mathrm{~V}$ and without negative bias $(0 \mathrm{~V})$. A liquid palm oil precursor was heated outside the chamber at $180^{\circ} \mathrm{C}$ by using hot platter (Stuart CB162). A vaporized of palm oil was pressured into the chamber using aquarium air pumps (GA8000). The amount of the vaporized palm oil, carrier gas argon used into were set to be constant at $114 \mathrm{~mL} / \mathrm{min}, 180 \mathrm{~mL} / \mathrm{min}$, respectively. For doping process, $150 \mathrm{mg}$ of boron was placed on an aluminium foil inside the furnace of chamber.

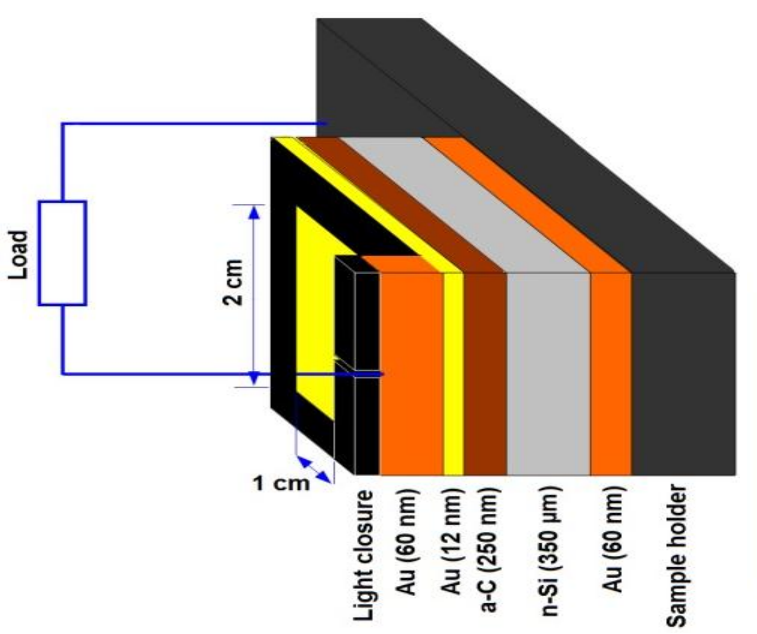

(a)

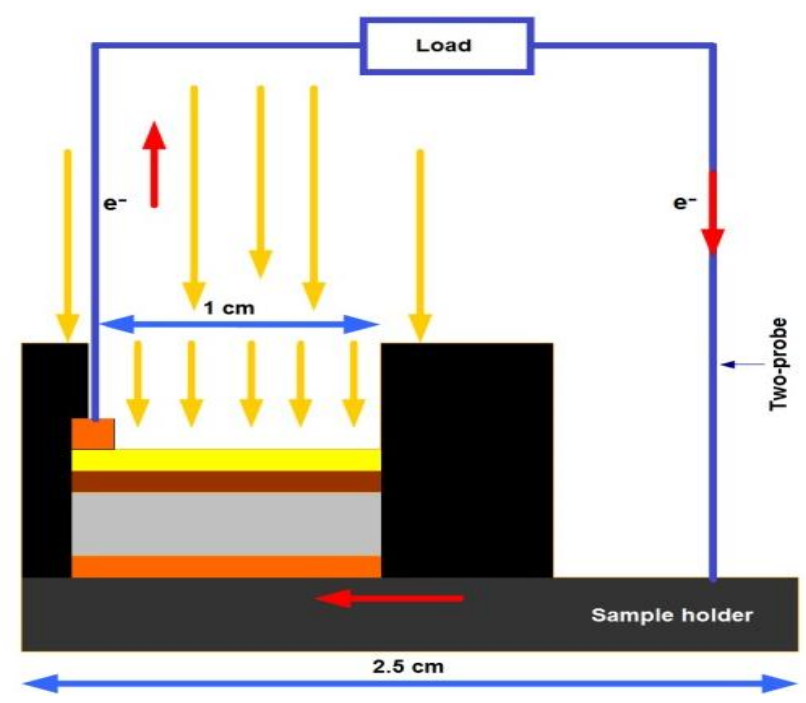

(b)

Figure 2 The measurement technique for heterojunction solar cell (Au/a-C/n-Si/Au and Au/a$\mathrm{C}: \mathrm{B} / \mathbf{n}-\mathrm{Si} / \mathrm{Au}$ ) 
In the evaluation of the fabricated solar cell device, the bottom and top sides of silicon were deposited with approximately 60 and $12 \mathrm{~nm}$ gold, respectively. Another gold film (thickness: $60 \mathrm{~nm}$ ) was deposited on the top surface of the $12 \mathrm{~nm}$ gold film to verify if the probe point established proper contact with the gold metal. Light closure was attached on top of the device (Fig. 2) to ensure that light strikes only the $2 \mathrm{~cm}^{2}$ target area. To establish a complete circuit, then other probe is connected to a conductive metal holder. Surface profiler (Veeco Dektak 150), FESEM (ZEISS Supra 40VP), and energy-dispersive spectroscopy (EDS), Atomic force microscopy ( AFM, XE-100 Park Systems) and Solar simulator (Bukuh Keiki EP200) were used to characterize the surface morphology, atomic level, and electronic properties, respectively.

\section{RESULT AND DISCUSSIONS}

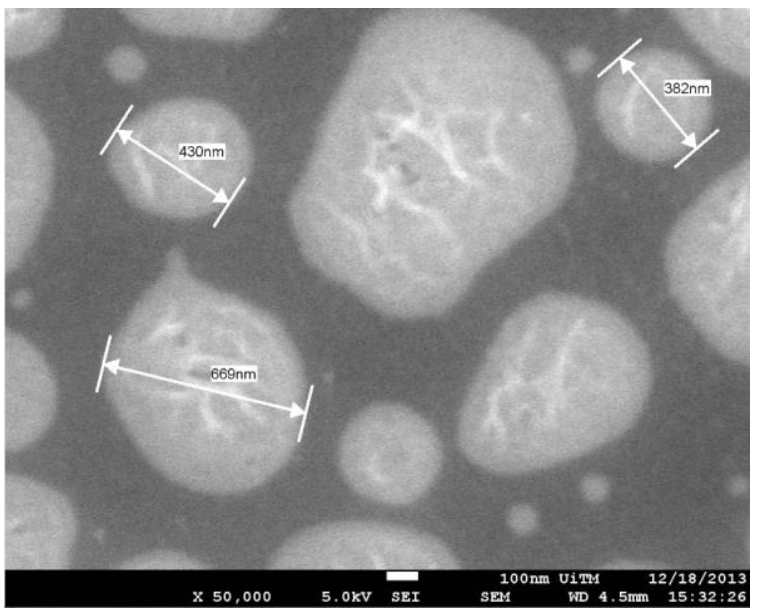

(a)

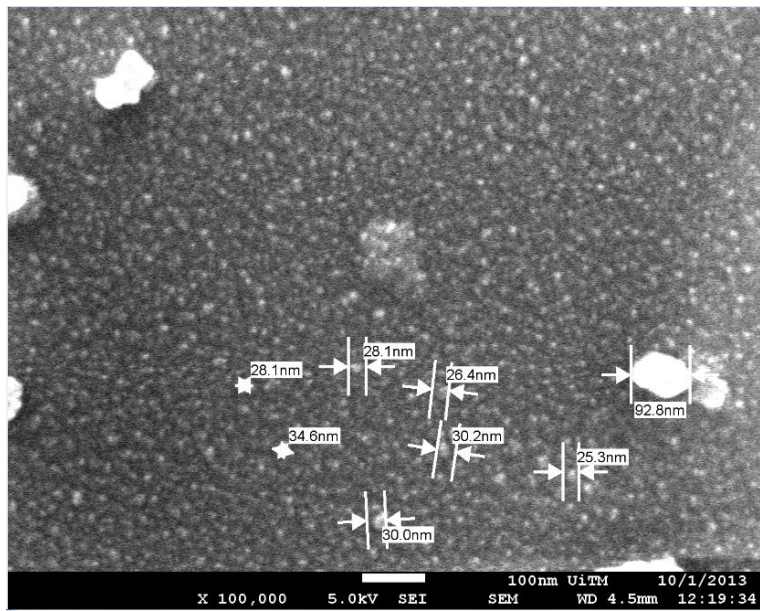

(b)

Figure 3 FESEM images of (a) as-deposited (a-C) and (b) boron-doped of a-C:B films

Fig. 3 (a) and (b) show the FESEM images of micro-structured and nano-structured of a-C and a-C:B films, respectively. The images were taken with magnification of $50 \mathrm{~K}$ and $100 \mathrm{~K}$ using $5.0 \mathrm{kV}$ voltage. The images in Fig. 1 (a) shows the irregular pattern of structure synthesized from pure hydrocarbon precursor of palm oil with the diameter in size of below 382-669 $\mathrm{nm}$ without the use of negative bias of $-20 \mathrm{~V}$. As can be observed from FESEM images, the miro-structured a-C film consists of irregularly scattered micro ball-like of agglomerated particles. In contrast, the nano-structured a-C:B film has particles in diameter of 28-34 $\mathrm{nm}$. As bias voltage of $20 \mathrm{~V}$ and boron applied, the size of particles becomes significantly decreased. This difference in the size of the surface film can be attributed to the ion bombardment during the growth of the films which is controlled by the applied of negative bias onto the substrate. More specifically, during the deposition of a-C:B film with applied of $-20 \mathrm{~V}$, an intense positive-ion bombardment on the growing film surface is occurred. The flux and the energy of these species affect the mechanisms that govern the incorporation of boron in the a-C network and the formation of a-C:B bonding groups. The negative bias of $-20 \mathrm{~V}$ increases the energy of the bombarding ions, enhancing the chemical reactions between different species and their mobility at the growing film surface. As a result, the high-energy gas ions dissociate the deposition carbon clusters affecting the boron distribution, and the bonding structure of the a-C:B film. Accordingly, without bias voltage $(0 \mathrm{~V})$ applied to substrate, the ions energy is too weak to penetrate into the growing surface and most of the ions are only trapped on the growing surface, resulting in the formation of the loose cross-linking [10,11] resulting to the irregularly scattered micro ball-like of agglomerated particles.

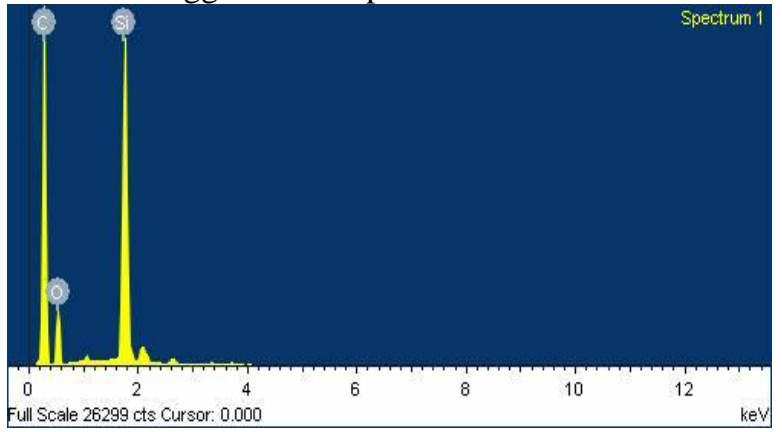

(a)

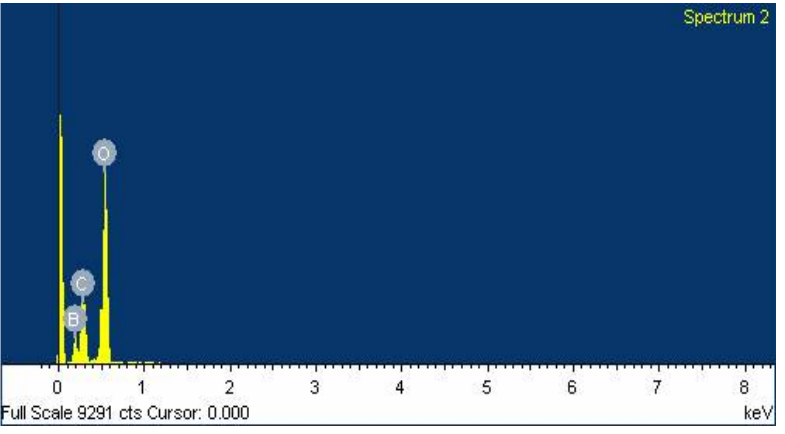

(b)

Figure 4 EDS results of (a) as-deposited (a-C) and (b) boron-doped of a-C films 
Fig. 4 (a) and (b) show the EDS images of micro-structured a-C film and nano-structured a-C:B film, respectively. The composition of carbon arise at $0.4 \mathrm{~K} \mathrm{eV}$ in a-C film while composition of boron together with carbon in a-C:B film arise at around 0.4 and $0.3 \mathrm{~K} \mathrm{eV}$, respectively. We observed the compositional element of carbon is quite similar with the compositional element of silicon and only small number of oxygen found in is EDS result. In contrast, the compositional element of carbon decrease as boron introduce in a-C film. With negative bias (in this case $-20 \mathrm{~V}$ ), the ion current drew towards the substrate increases along with the flux of neutral and charged species. This further cause an increase in preferential nucleation sites so that individual grain growth is arrested, hence expected to reduce the grain size as shown in Fig. 3 (b). However, the content of the elements are decreased, which possible allowed the grains to expand, since with increase in dopant content, the crystallite size of a-C:B film decrease. The same phenomena were reported $[6,12,13]$ for TiN-MoS $\mathrm{x}_{\mathrm{x}}$ and $\mathrm{CrB}_{2}-\mathrm{MoS}_{\mathrm{x}}$ composite coating when the increasing of negative bias.

AFM images shown in Fig. 5 illustrate the effect of the bias voltage and without bias voltage on the surface roughness and feature. The films deposited at all conditions show very smooth with agglomerated 'island' form. The films deposited without bias $(0 \mathrm{~V})$ are denser as compared to negative bias of $-20 \mathrm{~V}$ but more higher of surface roughness as compared with the applied of negative bias voltage $(-20 \mathrm{~V})$ as shown in Table 1 . In the case of applied the substrate without negative bias $(0 \mathrm{~V})$, the denser of particle at atomic level is attributed by the combination of unwanted macro-particles and neutral atoms. Most of the unwanted maro-particles and neutral atoms are remained under deposition temperature at $350^{\circ} \mathrm{C}$. While the surface of a-C:B film became smoother with applied of negative bias $(-20 \mathrm{~V})$, resulting in an obvious reduction in surface roughness from $7.605 \mathrm{~nm}$ to $0.386 \mathrm{~nm}$. The decreasing tendency of surface roughness with increasing of negative bias voltage can be suggested by the energy of impinging ions to the growing film that help improve the roughness by the surface diffusion $[10,14]$.

Table 1.Surface roughness of micro-structured of a-C film and nano-structured of a-C:B film

\begin{tabular}{|c|c|}
\hline Bias voltage $(\mathbf{V})$ & Surface roughness (nm) \\
\hline 0 & 8.605 \\
\hline-20 & 0.486 \\
\hline
\end{tabular}

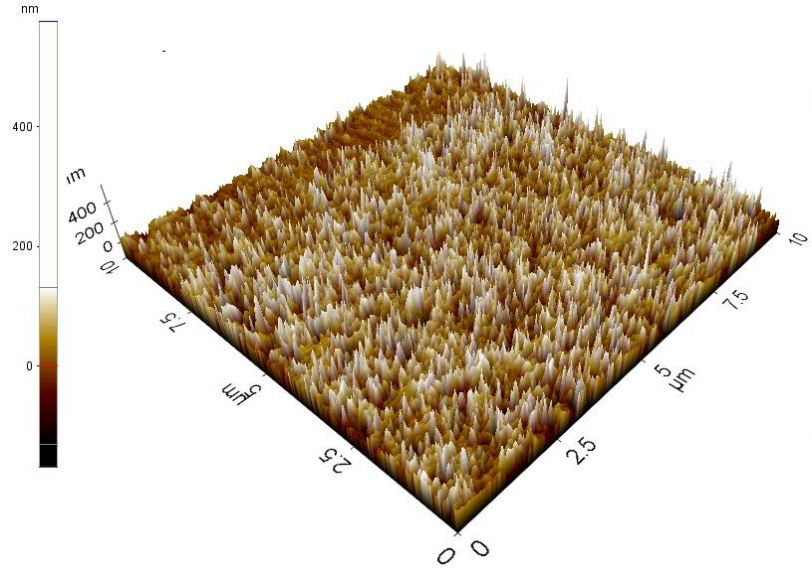

(a)

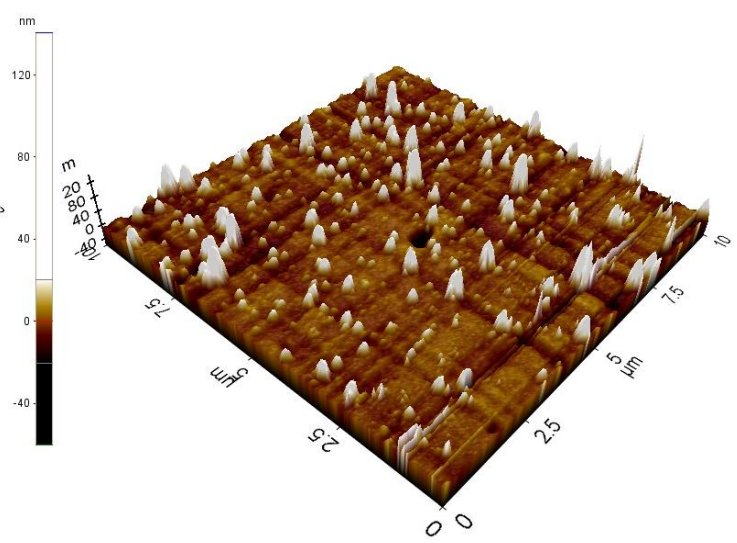

(b)

Figure 5 Two typical 3-dimentional AFM images of (a) as-deposited a-C film and (b) boron doped a-C film

The current density-voltage $(J-V)$ characteristics of $\mathrm{Au} / \mathrm{a}-\mathrm{C} / n-\mathrm{Si} / \mathrm{Au}$ and $\mathrm{Au} / \mathrm{a}-\mathrm{C}: \mathrm{B} / n-\mathrm{Si} / \mathrm{Au}$ solar cells in dark environment are shown in Fig. 6 (a). The Au/a-C/n-Si/Au and Au/a-C:B/n-Si/Au solar cells display rectifying curves, which indicate the formation of heterojunction between the a-C:B film and silicon. The a-C and a-C:B layers acted as a $p$-type semiconductor with respect to silicon substrate, thus forming the rectifying curve. The reverse saturation current, which is low as compared with the forward current, gradually increases with reverse bias (photocurrent increases). These behaviors can be attributed to the generation of minority carriers within the depletion region. At forward bias, the current increases exponetially, indicating a good quality of $p-n$ junction. The ideality factor is approximatelty 2 , indicating the dominance of the recombination current rather than the diffusion current. Many deviations from the ideal $p-n$ characteristics are observed, which can be due to the high low doping efficiency and posses complex structure and high density of defects $[14,15,16]$. 


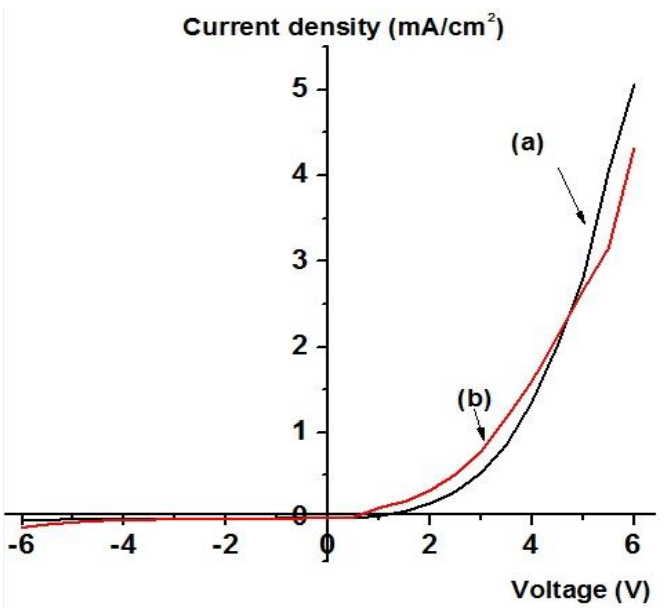

(a)

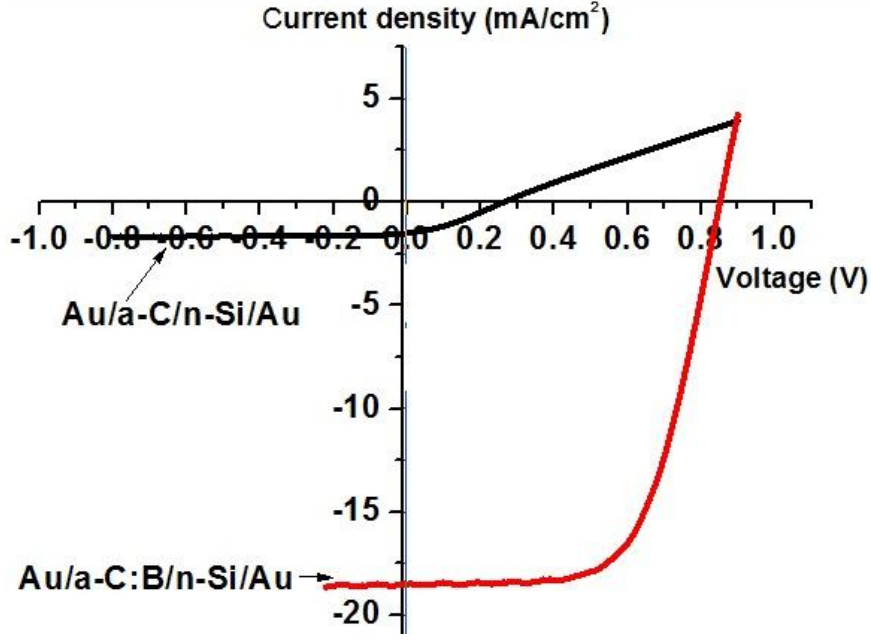

(b)

Figure 6 The $\mathrm{Au} / \mathrm{a}-\mathrm{C} / \mathrm{n}-\mathrm{Si} / \mathrm{Au}$ and $\mathrm{Au} / \mathrm{a}-\mathrm{C}: \mathrm{B} / \mathrm{n}-\mathrm{Si} / \mathrm{Au}$ solar cells under dark and illumination at negative bias of $0 \mathrm{~V}$ an $\mathrm{d}-20 \mathrm{~V}$

The $I-V$ characteristics of $\mathrm{Au} / \mathrm{a}-\mathrm{C} / n-\mathrm{Si} / \mathrm{Au}$ and $\mathrm{Au} / \mathrm{a}-\mathrm{C}: \mathrm{B} / n-\mathrm{Si} / \mathrm{Au}$ devices under illumination at $100 \mathrm{~mW} / \mathrm{cm}^{2}$ are illustrated in Fig. 6 (b). A dissimilar trends in the form of curves are observed for microstructured film used for $\mathrm{Au} / \mathrm{a}-\mathrm{C} / n-\mathrm{Si} / \mathrm{Au}$ solar cell and nano-structured film used for $\mathrm{Au} / \mathrm{a}-\mathrm{C}: \mathrm{B} / n-\mathrm{Si} / \mathrm{Au}$ solar cells by the. The obtained curve of $\mathrm{Au} / \mathrm{a}-\mathrm{C} / n-\mathrm{Si} / \mathrm{Au}$ solar cell is less broad and small area as compared with the obtained curve of $\mathrm{Au} / \mathrm{a}-\mathrm{C}: \mathrm{B} / n-\mathrm{Si} / \mathrm{Au}$ solar cell.

A slightly broad curve indicates reduced area (fill factor, FF) or maximum output power, and thus, the overall conversion efficiency is minimized. This phenomenon is attributed to series and shunt resistances, which are caused by metal contact and material defect, respectively. The open circuit voltage $\left(\mathrm{V}_{\text {oc }}\right)$, current density $\left(\mathrm{J}_{\mathrm{SC}}\right)$, fill factor $(\mathrm{FF})$ and efficiency $(\eta)$ of $\mathrm{Au} / \mathrm{a}-\mathrm{C} / \mathrm{n}-\mathrm{Si} / \mathrm{Au}$ is $\mathrm{V}_{\mathrm{oc}}, \mathrm{J}_{\mathrm{SC}}, \mathrm{FF}$ and $\eta$ is $0.265 \mathrm{~V}, 1.505 \mathrm{~mA} / \mathrm{cm}^{2}, 0.327$, and $0.1302 \%$, respectively. Meanwhile, the $\mathrm{V}_{\mathrm{OC}}, \mathrm{J}_{\mathrm{SC}}, \mathrm{FF}$ and $\eta$ were $0.272 \mathrm{~V}, 14.9 \mathrm{~mA} / \mathrm{cm}^{2}, 0.336$, and $1.543 \%$, respectively. It was observed that nano-strcutured a-C:B film used as the p-type in heterojunction solar cell produces higher convension efficiency than micro-strcutured a-C film.

The series resistance results in voltage drop, thus preventing full photovoltaic voltage across the external load; likewise, series resistance affects open circuit voltage $\left(\mathrm{V}_{\mathrm{OC}}\right)[25,31]$. By contrast, internal resistance of material (shunt resistance) is due to the device edges and grain boundaries [14-16]. Shunt resistance significantly contributes to the reduction of solar cell performance. In shunt resistance, a fraction of photogenerated carries are diverted away from the external load, thereby reducing current density $\left(\mathrm{J}_{\mathrm{SC}}\right)$. Series resistance can be minimized by introducing metal contact based on grid metal arrangement in commercialized silicon solar cells. Although metal contact arrangement in the solar cell configuration in the present study is attributed to high series resistance, which reduces the overall solar cell efficiency, our objective is to prove the nano-structured a-C film doping with boron from hydrocarbon source of natural palm oil can also be applied in the fabrication of heterojunction solar cells.

The electronic properties of Au/a-C/n-Si/Au solar cell, including its open $V_{\mathrm{oc}}, J_{\mathrm{sc}}, \mathrm{FF}$, and efficiency are presented in Fig. 6 (b). Low $V_{\mathrm{oc}}$ and $J \mathrm{sc}$ are found for micro-strcutured a-C film, which diretly indicate low FF and conversion efficiency. The low $V_{\text {oc }}$ and $J_{\text {sc }}$ values are attributed to the low built-in voltage, which are caused by the high amount of defect in the micro-strcutured a-C film. The electronic properties of $\mathrm{Au} / \mathrm{a}-\mathrm{C}: \mathrm{B} / n-$ $\mathrm{Si} / \mathrm{Au}$ solar cells remarakbly improved by the increase in the DC bias of the substrate. The Au/a-C:B/n-Si/Au solar cells fabricated through the deposition at $-20 \mathrm{~V}$ applied bias shows the highest conversion efficiency. The improvement of convension efficiency can be attributed to the successful boron incorporation, which increases the number of excess carriers in the nano-strcutured a-C:B film. The bombardment of ions produced by $-20 \mathrm{~V}$ is important in minimizing defects. The reduction of defects increases the built-in voltage, thereby prolonging the lifetime of excess carriers and providing wide difussion. Although the energy-conversion efficiencies of the fabricated solar cell devices are considerably low, the present study presents a viable alternative through the use of natural palm oil precursor in developing solar cells. Moreover, the energy-conversion efficiency achieved in this study (deposition at $-20 \mathrm{~V}$ applied bias) is higher than that reported by Tian. $(\eta=0.3 \%)$ [16] and Hayashi, $(\eta=0.04 \%)[17]$. 
IV

CONCLUSIONS

The micro and nano-structured of a-C and a-C:B films using novel precursor of palm oil for solar cell applications was presented. FESEM revealed films deposited with negative bias voltage of $-20 \mathrm{~V}$ had small particle in nano size in the range of $28-52 \mathrm{~nm}$ as compared without bias voltage $(0 \mathrm{~V})$. The EDS showed the existing of carbon in micro-structured a-C film and boron with carbon in nano-structured a-C:B film. Negative DC bias can improved the structural properties of the nano-strcutured size of particles and showed the nanostuctured film gave significant increment of energy conversion efficiency through the ion bombardment effect of the negative bias $(-20 \mathrm{~V})$. Solar simulator analysis results showed an open circuit voltage $\left(\mathrm{V}_{\mathrm{OC}}\right)$, current density $\left(\mathrm{J}_{\mathrm{SC}}\right)$, fill-factor(FF) and conversion efficiency $(\eta)$ of $\mathrm{Au} / \mathrm{a}-\mathrm{C} / \mathrm{n}-\mathrm{Si} / \mathrm{Au}$ were $264.62 \mathrm{mV}, 1.50434$ $\mathrm{mA} / \mathrm{cm}^{2}, 0.32632$, and $0.130154 \%$, respectively. Meanwhile, the $\mathrm{V}_{\mathrm{OC}}, \mathrm{J}_{\mathrm{SC}}, \mathrm{FF}$ and $\eta$ of Au/a-C:B/n-Si/Au solar cell were $271.25 \mathrm{mV}, 14.91723 \mathrm{~mA} / \mathrm{cm}^{2}, 0.33582$, and $1.542622 \%$, respectively. The conversion efficiency was increased as constant negative bias of $-20 \mathrm{~V}$ applied for doping boron into a-C film. Although the conversion efficiency of heterojunction solar cells are considerably low, it shows a good prospect of hydrocarbon palm oil as the carbon source for synthesis the nano and micro-structured a-C film as a p-type film in photovoltaic heterojunction solar cell applications.

\section{Acknowledgements}

The authors thank to Ministry of Higher Education (MOHE) Malaysia for the scholarship, Universiti Teknologi MARA, Kota Samarahan Sarawak and Research Management Institute (RMI) Universiti Teknologi MARA (UiTM) for the facilities.

\section{REFERENCES}

[1] A.B. Suriani, A.A. Azira, S.F. Nik, Roslan Md Nor, and M. Rusop, Synthesis of vertically aligned carbon nanotubes using natural palm oil as carbon precursor, Material Letters, 63, 2009, 2704-2706.

[2] S. Paul, and S.K. Samdarshi, A green precursor for carbon nanotube syhthesis, New Carbon Materials, 26, $2011,85-88$.

[3] J. Podder, M. Rusop, T. Soga, T. Jimbo, Boron doped amorphous carbon films grown by r.f. PECVD under different partial pressure, Diamond and Related Materials, 14, 2005, 1799-1804.

[4] Dayana Kamaruzaman, Nurfadzilah Ahmad, ishak Annuar, and Muhamad Rusop, Semiconducting Properties of Nanostructured Amorphous Carbon Thin Films Incorporated with Iodine by Thermal chemical Vapor Deposition, Japanese Journal of Applied Physics, 52, 2013, 11.

[5] Rusop, M., et al., Effect of Boron Weight Percentages in the Target of Pulsed Laser Deposition on the Preparation of Boron-Doped Amorphous Carbon Films, Surface Review and Letters, 2005, 12(01), 27-34.

[6] S. Gangopadhyay, R. Acharya,A. K. Chattopadhyay, S. Paul, Effect of substrate bias voltage on structural and mechanical properties of pulsed DC magnetron sputtered TiN-MoS ${ }_{x}$ composite coatings, Vacuum, 84, 2010, 843-850.

[7] S. Kassavetis, S. Laskarakis, S. Logothetidis, Effect of ion bombardment and hydrogen pressure during deposition on the optical properties of hydrogenated amorphous carbon thin films, Diamond and Related Materials, 20, 2011, 109-114.

[8] Xiufeng Tang, fa luo, fang Ou, Wangcheng Zhou, Dongmei Zhu, and Zhibin Huang, Effect of negative bias substrate voltage on the structure and properties of aluminium oxide films prepared by DC reative magnetron sputtering, Applied Surface Science, 259, 2012, 448-453.

[9] A. Bubenzer, B. Dischler, G. Brandt, P. Koids, rf-plasma deposited amorphous hydrgenated hard carbon thin films: preparation, properties, and applications, Journal of Applied Physics, 54, 1983, 4590.

[10] Peng Wang, Xia Wang, Youming Chen, Guangan Zhang, Weimin Liu, Junyan Zhang, The effect of applied negative bias voltage on the structure of Ti-doped a-C:h films deposited by FCVA, Applied Surface Science, 253, 2007, 3722-3726.

[11] E. Liu, L. Li, B. Blainpain, Residual stresses of diamond and diamondlike carbon films, Journal of Applied Physics, 98, 2005, 073515 .

[12] F. Buebuel, I. Efeoglu, E. Arslan, The effect of bias voltage and working pressure on S/Mo ratios at MoS ${ }_{2}$ Ti composite films, Applied Surface Science, 2007, 253-44515-9.

[13] M. Sakaki, T. Sakakibara, Ionization and reaction mechanism of a reactive cathodic arc deposition of TiN., IEEE Trans Plasma Science, 1994, 22

[14] M. S. Leu, S. Y. Chen, J. J. Chang, et al. Diamond-like coatings prepared by the filtered cathodic arc technique for minting application, Surface Coating Technology,177-178, 2004, 566.

[15] Rusop, M., et al., Preparation and characterization of boron-incorporated amorphous carbon films from a natural source of camphoric carbon as a precursor material, Applied Surface Science, 252, 2005, 1693-1703.

[16] X. M. Tian, M. Rusop, Y. Hayashi, T. Soga, T. Jimbo, and M. Umeno, A photovoltaic cell from p-type boron-doped amorphous carbon film, Solar Energy Materials and Solar Cells, 77, 2003, 105-112.

[17] Y. Hayashi, S. Ishikawa, T. Soga, M. Umeno, and T. Jimbo, Photovoltaic characteristics of boron-doped hydrogenated amorphous carbon on n-Si substrate prepared by r.f. plasma-enhanced CVD using trimethlboron, Diamond and Related Materials, 12, 2003, $687-690$ 